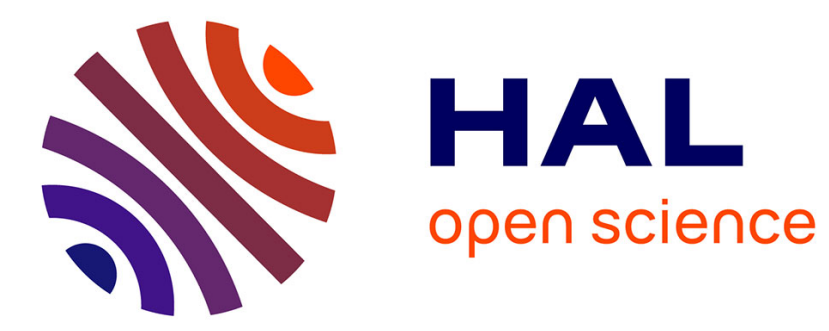

\title{
Le monument des Suovétauriles de Beaujeu (Rhône) Paul Veyne
}

\section{To cite this version:}

Paul Veyne. Le monument des Suovétauriles de Beaujeu (Rhône). Gallia - Fouilles et monuments archéologiques en France métropolitaine, 1959, 17 (1), pp.79-100. 10.3406/galia.1959.2257 . hal01924484

\section{HAL Id: hal-01924484 \\ https://hal.science/hal-01924484}

Submitted on 3 Mar 2020

HAL is a multi-disciplinary open access archive for the deposit and dissemination of scientific research documents, whether they are published or not. The documents may come from teaching and research institutions in France or abroad, or from public or private research centers.
L'archive ouverte pluridisciplinaire HAL, est destinée au dépôt et à la diffusion de documents scientifiques de niveau recherche, publiés ou non, émanant des établissements d'enseignement et de recherche français ou étrangers, des laboratoires publics ou privés.

\section{(이) $\$$}

Distributed under a Creative Commons Attribution - NonCommercial - NoDerivatives| 4.0 


\title{
LE MONUMENT DES SUOVÉTAURILES DE BEAUJEU (Rhône)
}

\author{
par M. Paul Veyne
}

On peut voir, au Musée de Lyon, un bas-relief qui n'est pas moins remarquable par son sujet - le sacrifice solennel de deux taureaux, d'un bélier et de deux truies - que par le nombre des personnages : près de trente figures.

Il est connu sous l'appellation de "monument des suovétauriles de Beaujeu ", du nom de la petite ville, située à une quarantaine de kilomètres au nord de Lyon, où il a été longtemps conservé. En dépit de l'intérêt qu'il présente, le relief est loin d'avoir la renommée qu'il mérite, et bien peu d'archéologues s'en sont occupés. On ne peut guère citer qu'Espérandieu, qui en donne une description rapide, et $\mathrm{M}^{\mathrm{m}} \mathrm{R}$ Ryberg, qui vient de lui consacrer deux pages de ses Rites of the State Religion in Roman Art ${ }^{1}$. Au terme de son étude, M ${ }^{\text {me }}$ Ryberg relève que "this sacrificial scene corresponds remarkably closely to the rites of the Roman fralres Arvales ", et conclut dubitativement que "the relief at Lyons does in fact represent either the Roman Arval rites or a local version of them ». C'est une autre interprétation que nous allons en proposer.

Long de $1 \mathrm{~m} .80$, taillé dans une pierre commune, le monument de Beaujeu est l'élément antérieur d'un couronnement d'autel (fig. 1).

Le lecteur se reportera au croquis coté que nous publions ici (fig. 2). La partie postérieure du monument, aux deux extrémités, est taillée de manière à ménager un assemblage en embrèvement sur toute la hauteur de la pièce ; en outre, une morlaise, qui recevail un goujon, vient renforcer l'assemblage. A chacune des deux extrémités venait donc s'encastrer, en équerre, un élément de couronnement semblable à celui que nous avons conservé ; ces deux éléments étaient à leur tour reliés entre eux par un quatrième, parallèle au premier, qui achevait le rectangle. Le tout posait sur le dé de l'autel.

(1) Espérandiet, Recueil général des bas-reliefs..., III, 1801 ; Inez Scott Ryberg, Riles of the Slale Religion in Roman Art, Amer. Acad. Rome, 1955, p. 115-117 et pl. 40. Une note de J. Descroix, Les "suovetaurilia " de Beaujeu, (Bulletin de l')Associalion lyonnaise de recherches archéologiques, 1935, p. 15-18, renseigne sur le remploi du relief comme linteau dans un porche d'église; je remercie M. P. Wuilleumier, qui m'a signalé cette note. 
Nolre élément de couronnement est décoré de reliefs figurés sur sa face anlérieure (ce sont ceux que nous allons étudier); et de reliefs décoralifs sur sa face postérieure (impossible à photographier), ainsi que sur les còtés, où ils sont interrompus par les embrèvements dans lesquels les éléments latéraux du couronnement venaient s'encastrer en équerre ; les reliefs décoralil's des còtés se prolongeaienl évidemment sur ces éléments latéraux, et ornaient leur face antérieure. Puisque l'élément que nous avons conservé portait une frise figurée, il devait constituer l'élément anlérieur du cadre qui couronnait l'aulel. Quant au décor qui court, sur la face postérieure du mème élément, il devait se continuer, lui aussi, sur les faces postérieures des élémenls latéraux.

Iu total, il faut se représenter un dé d'autel, surmonté d'une sorte de rambarde sur les quatre còtés: Cette rambarde est décorée da reliefs lant vers l'intérieur que vers l'extérieur du cadre qu'elle constitue ; vers l'intérieur, ces reliefs sonl décoratifs ; de même vers l'extérieur, sauf sur la face principale de l'autel, où ils sont figurés.

Par ailleurs, la partie inférienre de notre ćlément, laquelle constitue son lit de pose el reposait sur le dé, porte, elle aussi, des reliefs. Mais ces reliefs, fails de rosaces, sont très plats, d'un travail médiocre, et très différents à tous points de vue des autres reliefs qui décorent l'élément; ils sont cerlainement une adjonction postérieure. Sclon toute vraisemblance, ils ont été exécutés à l'époque où l'élément fut remployé dans une église de Beaujeu comme linteau : la face inférieure était alors visible, et reçut celle médiocre décoralion de rosaces.

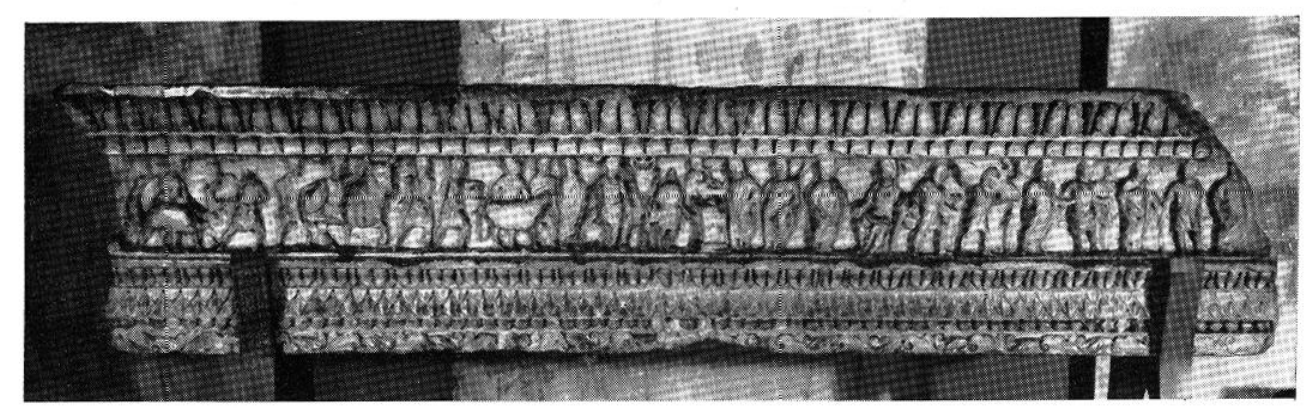

Fig. 1. - - Le Monument de Beanjen (Rhóne) au musce de Lyon.

Considérons la frise (fig. 1). A première vue, la scène qui y est représentéc est incohérente : à gauche une pompa amène deux taureaux, un bélier et une truie vers un autel sur lequel opère un prêtre voilé; à droite une seconde pompa, où figure une autre truie, semble s'éloigner de l'autcl, lequel est au centre du tableau. En réalité, il s'agit d'une narration continue dans le lemps. Les deux processions n'en font qu'une et ne s'ordonnent pas par rapport à l'autel ; cette pompa unique, et le sacrifice qui est célébré devant l'autel, sont deux scèncs chronologiquement distinctes, qui se sont succédé dans le temps. Vais le sculpteur a inséré, au milieu de la procession, la représentation du sacrifice qui en était vraisemblablement la conclusion; ce qui créc la fausse apparence d'une pompa coupée en deux tronçons. La transposilion, vers le centre d'une 

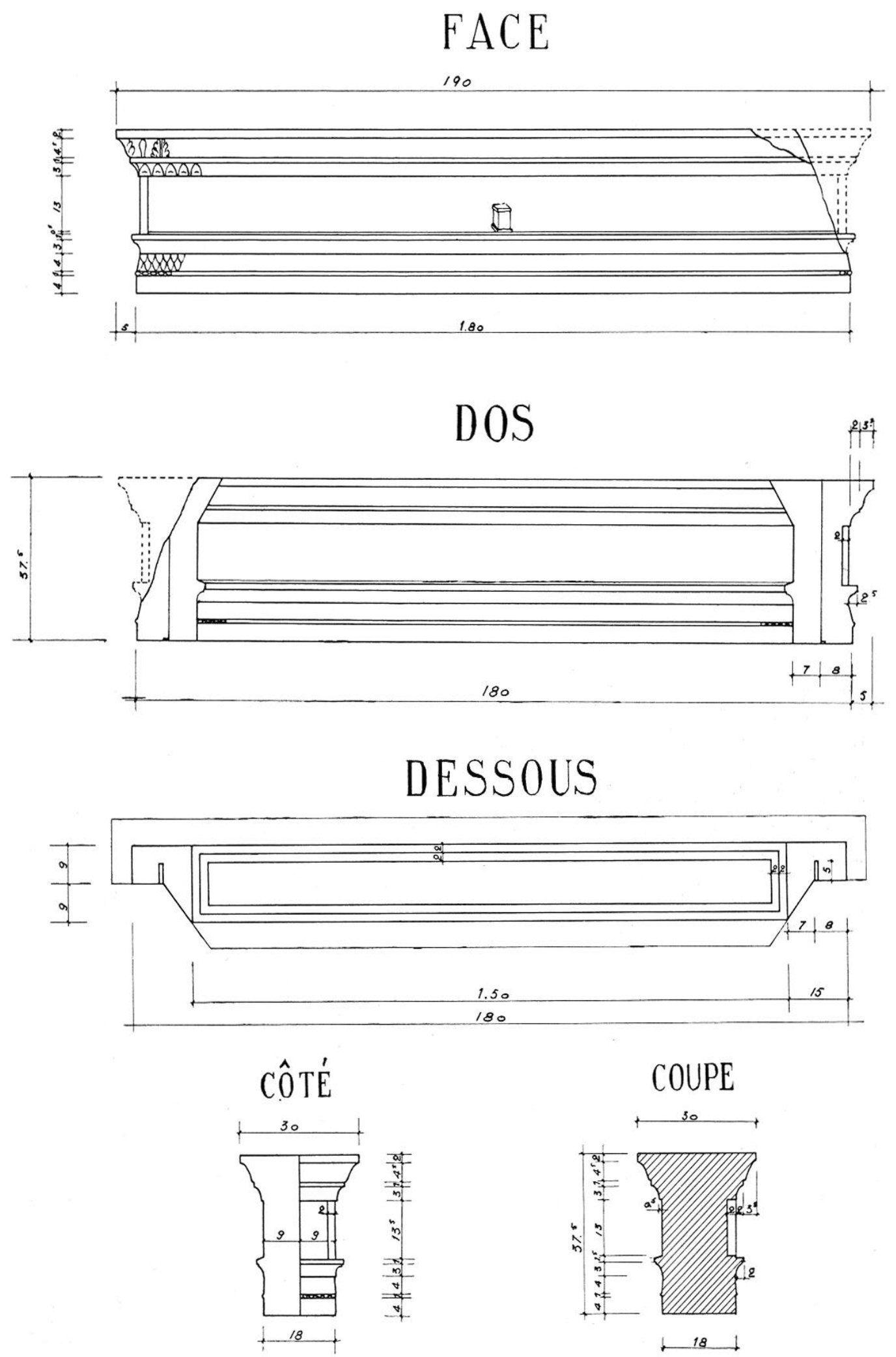

Fig̣. 2. - Relevé du monument de Beaujeu. 
composition, d'une scène qui se placerait la dernière dans le temps, se retrouve, par exemple, sur un certain nombre de sarcophages "de généraux ": la scène de sacrificium en occupe souvent le centre, ce qui est chronologiquement absurde ${ }^{2}$.

Décrivons d'abord la pompa, puis le sacrifice (fig. 3,4 et 5 ).

La Pompa. - Interrompue en son milieu par la scène sacrificielle, elle se déroule sur toute la longueur du relief.

Un corlège s'avance de gauche à droite; nous allons le dćcrire, en le remontant de droile à gauche. Viennent en tète deux licteurs en loge (nos 1 et 3 , fig. 3 ), qui portent un faisceau sur l'épaule gauche ${ }^{3}$; l'un d'eux tient en outre une baguelle ou commetaculum.

Ils encadrent un homme vètu d'une tunique courte, tel un minister ( $\mathrm{n}^{\mathrm{o}} 2$, fig. 3), qui a dans la main gauche un objet peu reconnaissable, capsa ou acerra; à la main droite, il tient un bàton épais qui touche presque le sol, el sur lequel il semble s'appuyer, par une fausse apparence qui a trompé Espérandieu. Mais un grand relief mutilé de Portogruaro, l'antique Concordia, permet de comprendre son geste ${ }^{4}:$ on y voit deux licteurs en sagum, avec faisceaux et commetaculum, qui précèdent un ministre en tunique courte, portant une hache sur l'épaule gauche, et lenant à la main droite un gourdin qu'il laisse pendre vers le sol (fig. 7). A Concordia comme à Beaujeu, il est clair que l'homme en tunique est un ministre du sacrifice, et que le gourdin, la capsa et la hache sont des instruments cultuels. L'usage d'assommer les bêtes offertes en sacrifice, avant de les égorger, est mainte fois attesté.

Les deux licteurs et le ministre sont suivis d'un logatus, esquissé en léger relief au second plan ( $\mathrm{n}^{\circ} 4$, fig. 3), et d'un nouveau ministre en tunique, qui porte dans les deux mains des ustensiles malaisés à identifier : peut-être un coffret, et une sorle d'encensoir $\left(\mathrm{n}^{0} 5\right.$, fig. 3). Nous verrons plus loin que le togatus doit être un magistrat municipal ; peut-être faut-il songer alors, à propos de l'encensoir, à un vers d'Horace qui décrit un duovir de Fundi, fier de sa toge prétexte et de la cassolette de braise, insignes de sa dignilés.

Ce groupe de personnages n'est pas sans rappeler un relief mutilé d'Osimo, l'antique Auximum ${ }^{6}$ : un licteur précède deux togali et un ministre en lunique qui porte le coutelas avec laquel il égorgera la victime (fig. 8). Les reliefs de Concordia, d'Auximum et de

(2) Ronexwadd, Celjer den stilwandel in der anloninischen Kunst, Abhandl. Preuss. Akad. Wiss., $193 \overline{5}, 3$, p. 5 .

(3) La trace du faisceau du premier licteur, enlevé par une cassure, se reconnail sur la photouraphie d'Espérandicu.

(4) Nolizie degli Scati, 1877 , p. 39 ; le relief est au musée de Portogruaro. Il en existe une photo chez Alinari. Voir encore un relief de Palestrina, avec deux licteurs et des ministri: G. MonerTr, Ara Pacis Auguslae, p. 296, fig̣. 198.

(5) Horacie, Salires, $1,5,35-36$ :

... insani ridentes praemia scribae,

praetextam et latum clavum prunaeque valillum.

(6) G. V. Gextrlit, Auximum, dans la collection Municipi e colnnie, 1955, pl. 12. Je remercie M. G. V. Gentili, Surintendant des Antiquités de la Sicile Orientale, qui m'a communiqué une photographie du relief. 


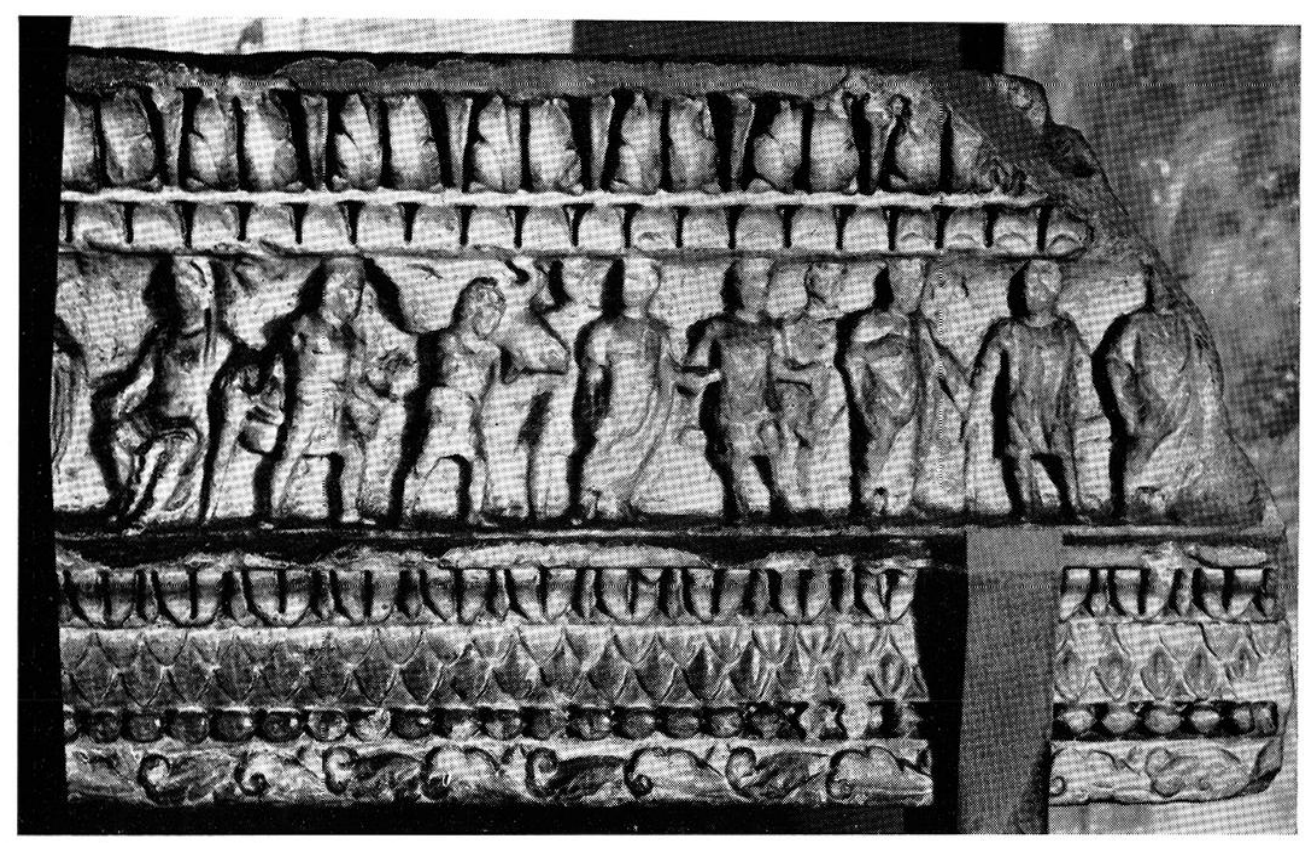
b VI
| 9
8
$\begin{array}{ll}7 & 6\end{array}$
54
$\begin{array}{lll}3 & 2 & 1\end{array}$

Fig. 3. - Détail, partic droite.

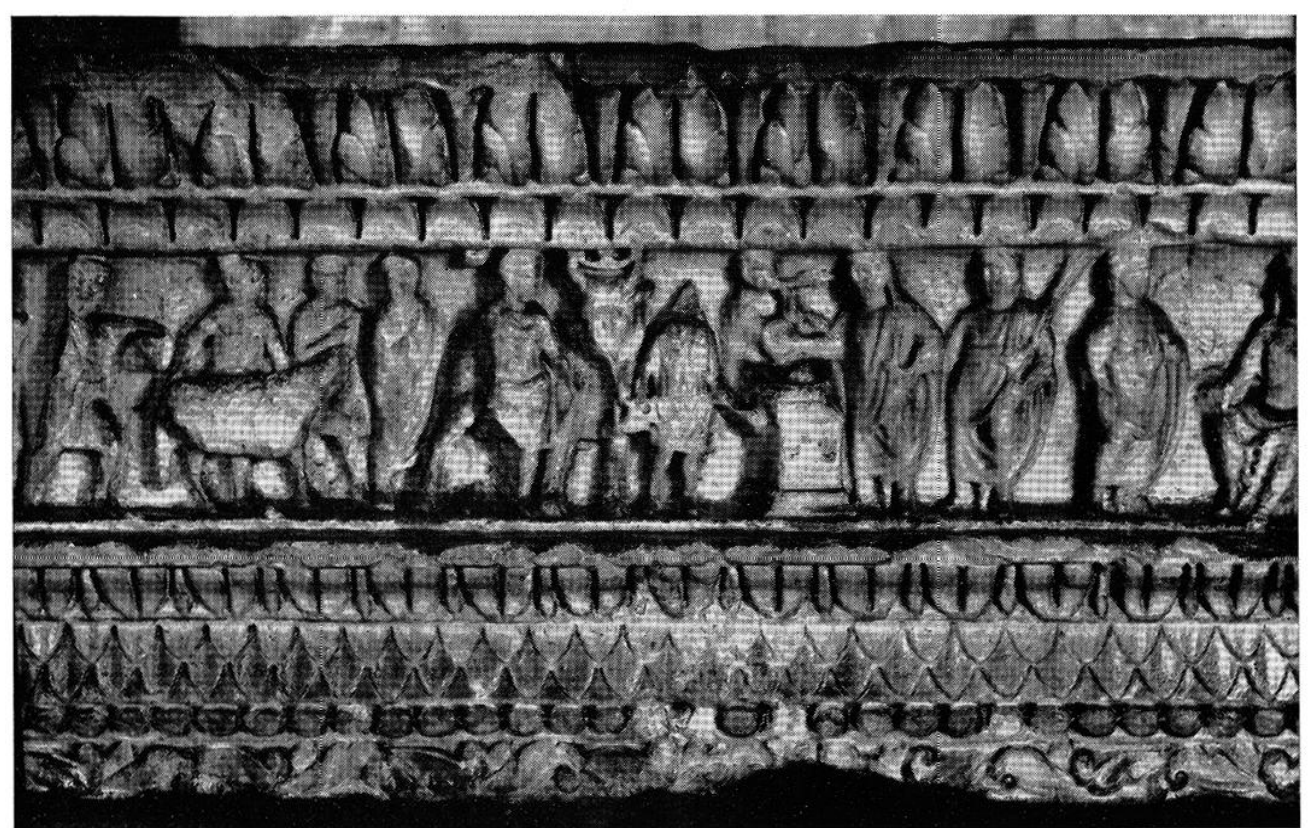

$13 \quad 12 \quad 11$

10

III II

I

IV

V

Fig. +. - Détail, partie centrale. 
Beaujeu sont évidemment des représentations de pompa municipale; les licteurs qui y apparaissent sont ceux de la cité.

S'avancent, mainlenant quatre hommes : un logatus tenant à la main droile un rouleau, symbole d'autorité ; il se retourne comme pour vérifier si le corlège le suit $\left(n^{0} 6\right.$, fig. 3). A ses côtés, un ministre en tunique, qui se cantonne à l'arrière-plan $\left(\mathrm{n}^{0} 7\right.$, fig. 3). Puis vient un autre ministre, portant sur l'épaule une truie vraisemblablement récalcitrante (no 8 , fig. 3 ). On aperçoit enfin un popa, nu jusqu'à la ceinture, la taille serrée dans le limus; de la main droite, il tient un vase; de la gauche, il brandit un maillet de sacrifice ( $\mathrm{n}^{0} 9$, fig. 3 ).

La figuration de la pompa est interrompue ici par la scène sacrificielle, à laquelle assiste, à droite, une divinité sur son tròne. Quand la pompa recommence, on voit un homme qui mène un taureau, lequel porte une mitre entre les cornes (junclus auro); on ne peut distinguer si la bête porte également un dorsuale; l'homme est en tunique (no 10, fig. 4). Il semble amener le taureau à l'autel, mais ce n'est qu'une apparence, car le prêtre n'en est encore qu'aux préliminaires du sacrifice; et les sacrificateurs ne sont pas là : ils marchent en tête de la procession et semblent faussement s'éloigner de celle scène de sacrifice qui a été transposée au centre de la composition.

Derrière le taureau viennent d'autres victimes. Deux ministres conduisent un bélier (nos 12 et 13, fig. 4). Un togatus les précède, qui se retourne comme pour vérifier le bon ordre du cortège ( $n^{0} 11$, fig. 4). Puis s'avance un homme en tunique qui marche à grands pas; dans ses mains, un objet indistinct ( $n^{\circ} 14$, fig. j). Derrière lui, un second taureau mitré est conduit ou poussé par trois hommes également vêtus de tuniques (nos 15,16 et 17, fig. 5). Enfin, deux ministres vêtus de mème font avancer une truie (nos 18 et 19 , fig. 5 ).

Des arbres, visibles à l'arrière-plan (de part et d'autre du no 19, fig. 5), indiquent que la pompa se déroule dans la campagne; telle est, en effel, la signification d'un décor d'arbres sur les sarcophages et sur les reliefs en général.

Le Sacrifice. - Sans doute est-il célébré également dans le lieu champêtre que parcourt la procession.

Un prêtre, en toge et tête voilée, répand sur un autel quadrangulaire le contenu d'une patère ( $\mathrm{n}^{\circ} \mathrm{I}$, fig. 4). Sur l'autel, un plat semble contenir un gàteau. Selon un cliché fréquent, un joueur de double flûte est debout derrière l'autel ( $\mathrm{n}^{0}$ II, fig. 4) ; près de lui, un camillus tient un gutlus et une patère ( $\mathrm{n}^{\mathrm{O}}$ III, fig. 4). Nous assistons à la libation qui prélude au sacrifice proprement dit.

Derrière le prêtre, et tourné comme lui vers l'autel, se tient un togatus (no IV, fig. 4) qui a sur l'épaule gauche un faisceau fait de deux verges, comme on en retrouve sur d'autres monuments ${ }^{7}$; ce licteur unique est, lui aussi, bien connu : c'est un maître de

(7) Relief de Melz, Espérandiet, V, 4313 ; relief de Capoue, G. Pesce, I rilievi dell anfileatro Campano, $n^{\circ} 25$; et J. IIecroox, dans Sludies Robinson, t. 2, p. 931 et pl. 88 ; diptyque consulaire, Delirrück, Consulardipt., p.. 4 ; are de Cottius à Suse, Éspéraxistel, I, 465. Sur la plaque B de la Chancellerie, le logalus maître de cérémonie, qui se tient près des Vestales, porte un commelaculum, et un faisceau fait de deux baguettes, qui se distingue bien du gros faiscean des licteurs en tunique qui figurent auprès de l'empereur, à droite : F. Maci, I rilievi flaci del Palazzo Cancelleria, pl. 4. 


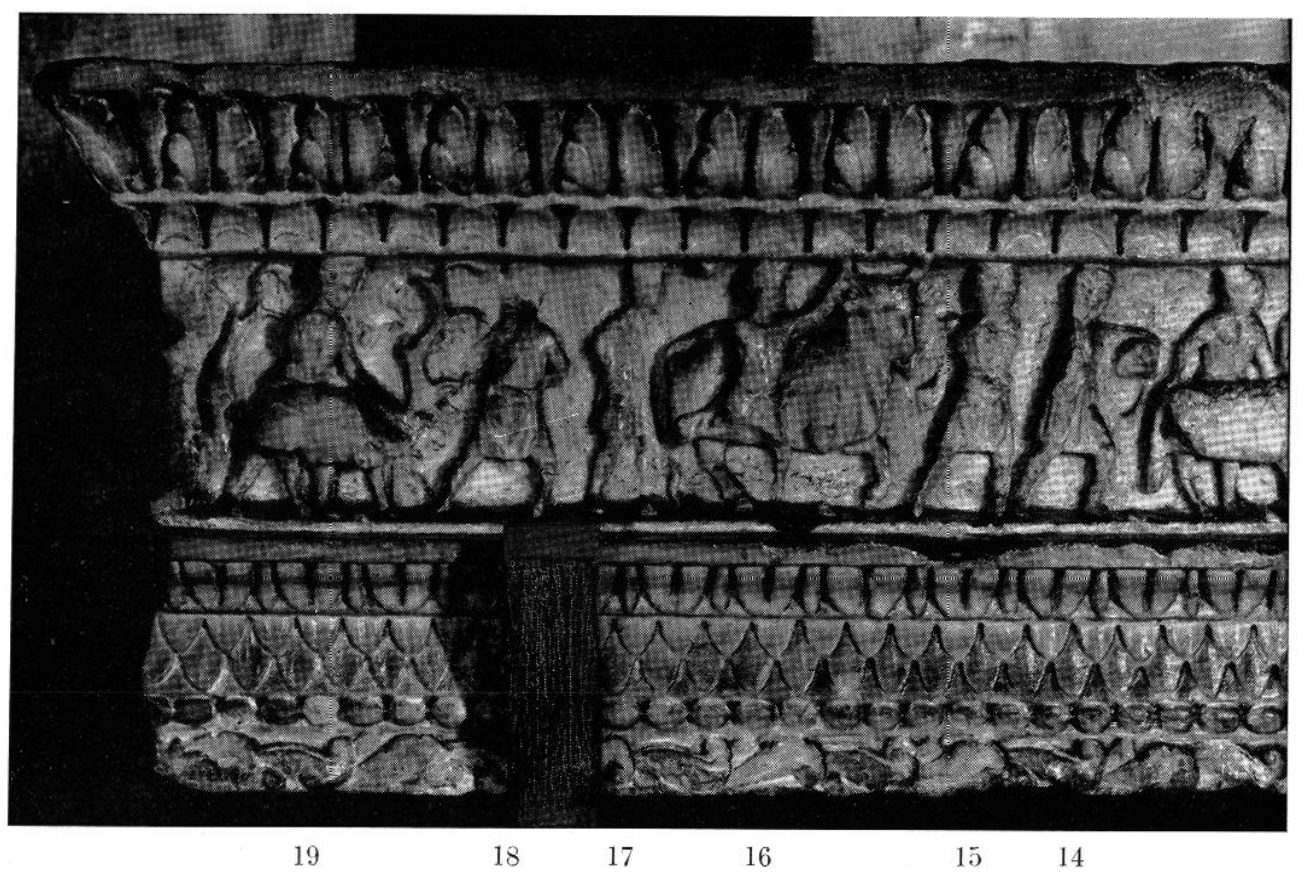

Fig. ว. - Détail, partie gauche.

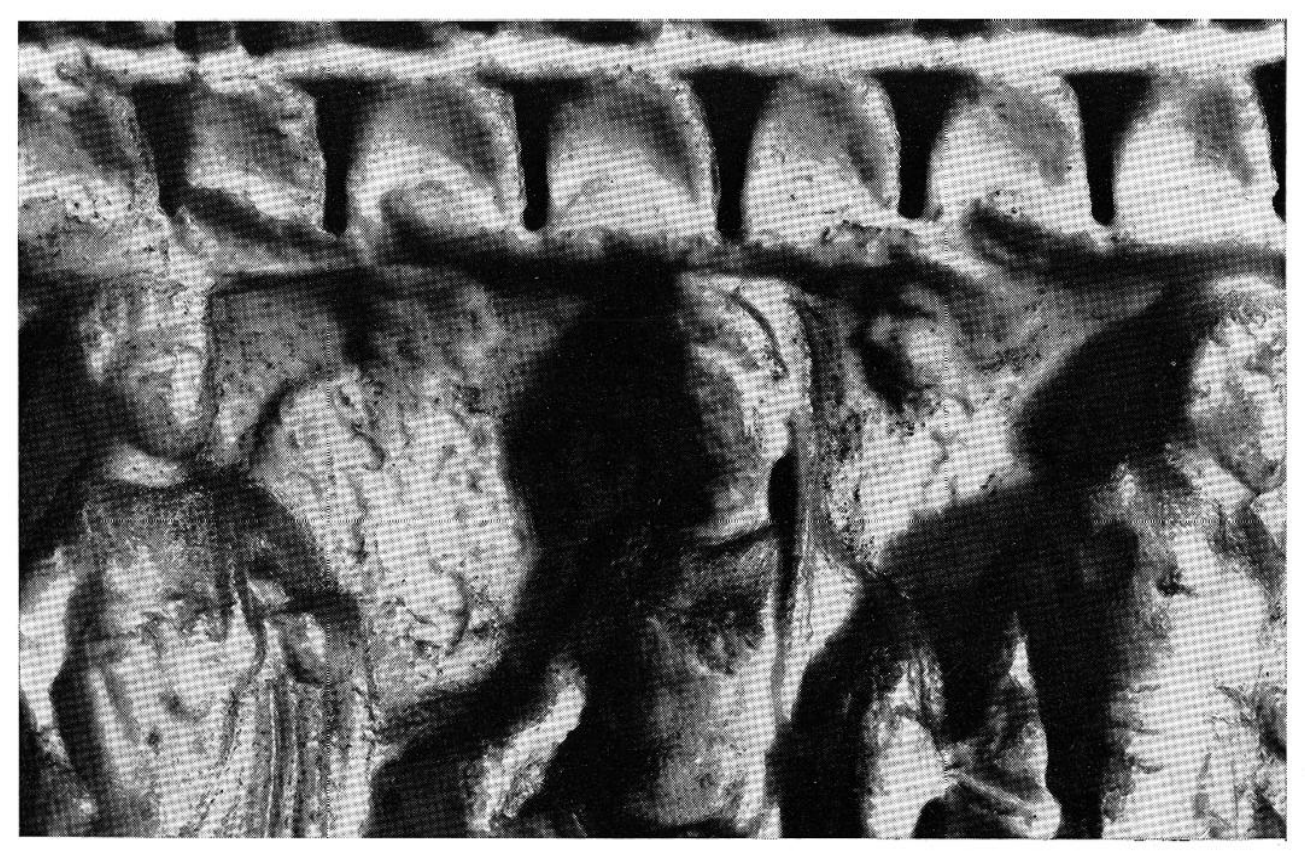

Fig. 6. - Détail : la déesse et les masques de Fleuves (VI, a, b, fig. 3). 
cérémonie, le lictor curiatius, comme l'appelle Mme Ryberg ${ }^{8}$; mais mieux vaudrait dire, peut-être, le liclor popularis ${ }^{9}$. Il préside à l'ordonnance d'une cérémonie officielle.

A droite de l'aulel et du prêtre, dont elle est séparée par le maìtre de cérémonie et par un personnage en toge ( $n^{0} \mathrm{~V}$, fig. 4), une déesse est assise sur son tròne ( $\mathrm{n}^{0} \mathrm{VI}$, fig. 4). Son vêtement est fait d'une tunique à manches longues et d'un manteau qui lui enveloppe les jambes; sous le voile qui couvre sa tête, sa cherelure est ceinte d'un diadème. Tournée vers l'autel, la déesse assiste comme numen praesens à la cérémonie qui se déroule en son honneur. L'homme en toge, un rotulus à la main, qui se tient devant elle et la regarde, lui fait sans doute les honneurs du sacrifice ( ${ }^{\circ} \mathrm{V}$, fig. 4).

A droite et à gauche de la tête de la divinité, deux figures en buste, indiquées par une simple silhouette, se détachent à peine du fond ( $a$ et $b$, fig. 3 et fig. 6). Leur lête imberbe, tournée vers la déesse, est moins sommairement modelée que leur corps ; ces deux figures ont la bouche ouverte; mais ce ne sont pas des personnifications des Vents, car leurs joues ne sont pas gonflées et elles n'ont pas d'ailes sur la tête. Nous verrons que ces silhouettes qui encadrent la divinilé assise sont probablement des personnifications de la Saône et du Rhòne, entourant Cérès, diadémée et voilée, qui siège sur son trône.

Pour l'instant, nous savons qu'il faut reconnaître, sur le relief, une procession suivic d'un sacrifice de suovétauriles; le lieu de la scène est champêtre ; enfin, comme le prouve la présence du licteur maitre de cérémonie, il s'agit d'une solennité publique.

On peut préciser : d'une solennité municipale, comme il ressort de la provenance du monument (une cérémonie de Rome est exclue), ainsi que de la présence de deux licteurs en tête du cortège. C'est le couple de licteurs bien connu des magistrats municipaux ${ }^{10}$; ils sont attachés aux duovirs, comme nous l'apprennent la lex Ursonensis, plusieurs reliefs et d'innombrables pierres tombales de magistrats des cités.

Il est alors probable que ces magistrats eux-mêmes doivent figurer dans le cortège. De fait, il semble possible de les identifier. Tous les personnages du relief sont vêtus de simples luniques, sauf huit, qui portent la toge. Parmi ces huit il faul compler d'abord

(8) Riles of State Religion, index, s. v. liclor curialius.

(9) Sur le lictor popularis, Dessad, Inscr. lal. sel., $n^{0} 1908,1909,1917$; Notiz. Scav., 1891, p. 34.

(10) Lex Ursonensis, cap. I.XII. Chaque duovir avait deux licteurs attachés à sa personne (comme il ressort également de nombreuses pierres funćraires où sont figurés les faisceaux), mais n'avait le droit de les produire que durant ses tours de charge; il en était de même, comme on sait, pour les consuls, dont l'alternance a servi de modèle à celle des duovirs, et qui produisaient leurs licteurs chacun à leur tour. Sur les monuments figurés où apparaissent les magistrats municipaux, les licteurs ne sont jamais plus de deux : ce sont ceux du duovir en exercice ce jour-là ; voir le relief de Capoue signalé note 7 , et un relief de Castel Sant'Elia publié par Ciotтi, Bullellino d'Arle, 1950, p. 1. et C. Axtr. Feslschrifl Egger, T. I, p. 189 ; notons encore l'autel dit de Vespasien à Pompéi, Bulletlino Comunale, 1939, p. 73 et Alli Ponlif. accad., Rendic., 23-24, 1947-1948, p. 174, ainsi qu'une scene de la Colonue Trajane, Cichorius, Traianssaüle, pl. LXI, section 220. Nous reviendrons sur la question dans un article à paraître sur l'iconographie des duovirs. 
les deux licteurs duoviraux et le maître de cérémonie, avec leurs faisceaux sur l'épaule $\left(n^{\circ} 1,3, I V\right)$; ainsi que le prètre qui fait unc libation à l'autel $\left(n^{n} I\right)$. Restent quatre logati. L'un d'eux s'avance en tète de la pomfa, derrière les licleurs (no 4); un autre, rotulus à la main, marche au milieu du cortège et se retourne comme pour vérifier si tout, est, en bon ordre ( $\mathrm{n}^{\circ}$ (i) ; un troisième fait de même, mais il n'a pas de rotulus ( $\mathrm{n}^{\circ} 11$ ); un quatrième et dernier, rolulus à la main, est debout à còté de la déesse et lui fait les honneurs du sacrifice ( $n^{\circ} \mathrm{V}$ ). Il est tentant de reconnaître en eux les quatre magistrats de la cité, parmi lesquels les duovirs jure dicundo seraient les deux hommes que distingue le port d'un olulus, symbole d'autorité (nos 6 et $V$ ). Un scul de ces duovirs se tient près de l'autel ( $n^{\circ} V$ ), et, tourné vers la déesse, semble le responsable du sacrifice; or on sait que les duovirs allernaient dans l'exercice de leur charge, comme les consuls; ils ne prenaient pas en commun la direction d'une cérémonie ou d'un acte public, mais chacun à son tour y présidait seul. Nous n'hésitons pas à proposer cette identification des quatre togati du relief, car l'expérience semble bien prouver que les reliefs ofliciels reproduisent avec soin les réalités institutionnelles, et que les artistes qui les exécutaient recevaient, à cet égard, les instruclions les plus précises ; les magistrats qui leur commandaient le monument pour la cité tenaient à y ĉtre représentés dans toute leur dignité.

De même, le prêtre en loge qui opère sur l'autel velato capite est certainement le pontife municipal $\left(n^{\circ} \mathrm{I}\right)$.

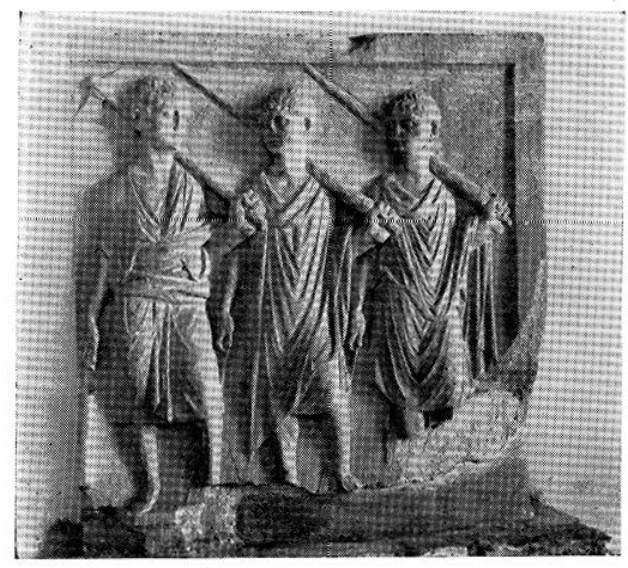

Fig. 7. - Bas relief de Concordia (Portogruaro, 1talie). Fragment de pompa municipale.

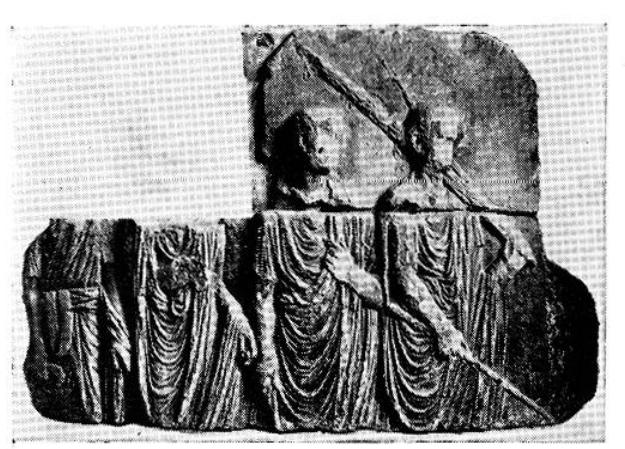

Fig. 8. - Auximum (Osimo, Italie). Fragment de pompa municipale. (Documenl obligeamment communique par M. G. V. Gentili).

Quoi qu'il en soit, la présence du couple de lictcurs duoviraux ct du maitre de cérémonie suffisent à faire reconnaître sur le relief une solennité municipale. En somme, nous avons affaire à un cortège rustique suivi de suovétauriles, et conduit par les officiels d'une ville municipale, ou en leur nom.

Quelle est cette ville ? La présence de licteurs indique qu'il ne peut s'agir que d'une ville de citoyens romains ou de Latins. La bourgade de Beaujeu, d'où provient le monument, est à peu près à mi-chemin entre Mâcon et Lyon, à une quarantaine de kilomètres au NNO de cette dernière cité (v. la carte fig. 12); 
elle peut donc se trouver sur l'antique territoire des Eduens, ou encore sur celui des Ségusiaves, dont les limites sont mal connues, ou enfin sur celui de Lyon, dont on ne sait jusqu'où il s'étendait vers le Nord. Nous avons donc le choix entre trois civitates: Autun chez les Eduens (ou Mâcon, si cette ville avait déjà le titre de cité à l'époque de notre relief) ; Forum Segusiavorum (F'eurs), chef-lieu des Ségusiaves; ct la colonie de Lyon.

Cette dernière cité cst la bonne. Sur le relief, la Cérès assise, à qui le sacrifice est dédié, est encadrée de deux figures en buste, deux silhouettes tournées vers elle, qui ont la bouche ouverte comme les masques ou silani qui décoraient les bouches de fontaines (fig. 3, $a$ et $b$; détail fig. 6). Or, sur un médaillon d'applique de la vallée du Rhône, est figurée la Tutelle de Lyon encadrée de deux bustes de fleuves (fig. 9) : "La Tutelle de Lugdunum, écrivent P. Wuilleumier et A. Audin, apparaît avec une couronne tourelée sur la tête... Deux bustes latéraux, qui crachent de l'eau à la manière des fleuves, symbolisent selon toute vraisemblance, non pas des Vents comme le croit M. Alföldi, mais le Rhône et la Saône "11. (V. fig. 10-11). Sur le relief de Beaujeu, les deux silani jouent, nous semble-t-il, le même rôle, la bouche ouverte pour laisser passer l'eau. Lyon était essentiellement la ville bâtie ad confluentes Araris el Rhodani. De même, la Mésopotamic au nom transparent est symbolisée, sur l'arc de Bénévent, par une femme qu'encadrent deux Fleuves couchés; sur des monnaies de Gallien, la ville de Siscia est représentée par les deux Fleuves, la Save et la Kulpa, au conlluent desquels elle est bâtie ; et, sur les monnaies d'Alexandrie, la personnification de la cité est entouréc de deux figures qui incarnent les deux ports de la ville ${ }^{12}$.

Nous proposons de reconnaitre, sur le relief de Beaujeu, Cérès, protectrice des récoltes du territoire lyonnais, encadrée par les silani du Rhône et de la Saône.

(11) P. Wunleumer et A. Aunn, Les médaillons d'applique gallo-romains de la vallée du Rhöne, Paris, 1952, p. 68 et fìr. 96, qui font allusion à A. ALFöı.Dr, Tonmodel und Reliefmedaillons alls den Donauländer, dans Laureae Aquincenses, 1, p. 10 ; voir encore F. CLNoxr, Recherches sur le symbolisme funeraire, p. 172. Les bustes de fleuves sont extrêmement fréquents, comme on sait, sur les mosaïques; et de nombreux silani ou masques qui décoraient des bouches de fontaines ont été retrouvés. Sur les silani, voir par ex. Eb. Fraexkel, Plaulinisches in Plaulus, p. 91, n. 1. Le relief de fontaine que nous reproduisons figg. 11, d'après un négatif de l'Institut Allemand de Rome, est commenté par K. Schauleviburg, Die Cameliden im Allerlum, Bonner Jahrb., 155-156, 1955-1956. p. 80 et pl. 9. Notons encore un denier de D. Silanus, avec au revers un silanus barbu, la bouche ouverte : H. Grtebrr, Coins of the Romun Republic in the B. M., vol. I, p. 248 et pl. N.X.II, nos 15 et 16 (ici fig. 10). Je remercie M. P. Wuilleumier, qui a bien voulu m'autoriser à reproduire la photographie du médaillon de la vallée du Rhòne.

(12) J. Beav.net, I.a religion romaine à l'apogée de l'Empire, Paris, 1955, t. I, p. 435, sur l'arc de Bénévent. Pour Siscia, A. ALFör.d, Die Vorherrschaft der Pannonnier, dans 25. Jahre römisch-germ. Kommission, p. 13. Pour les monnaies d'Alexandrie, R. S. Poole, Greeli Coins in the B. M., Alerandria, p. I.xxxiII. 


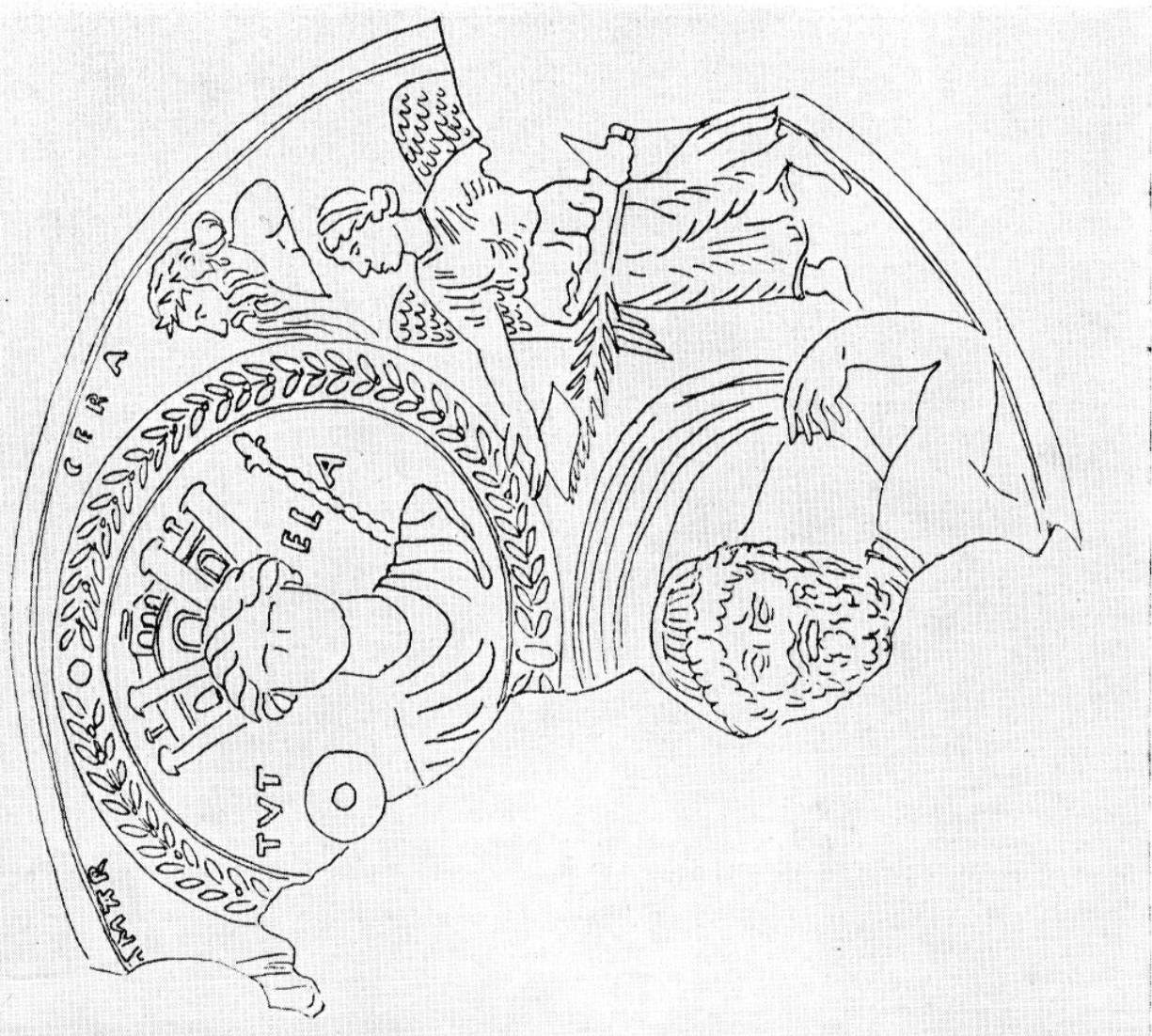

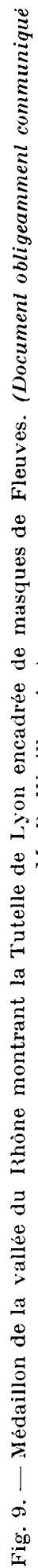

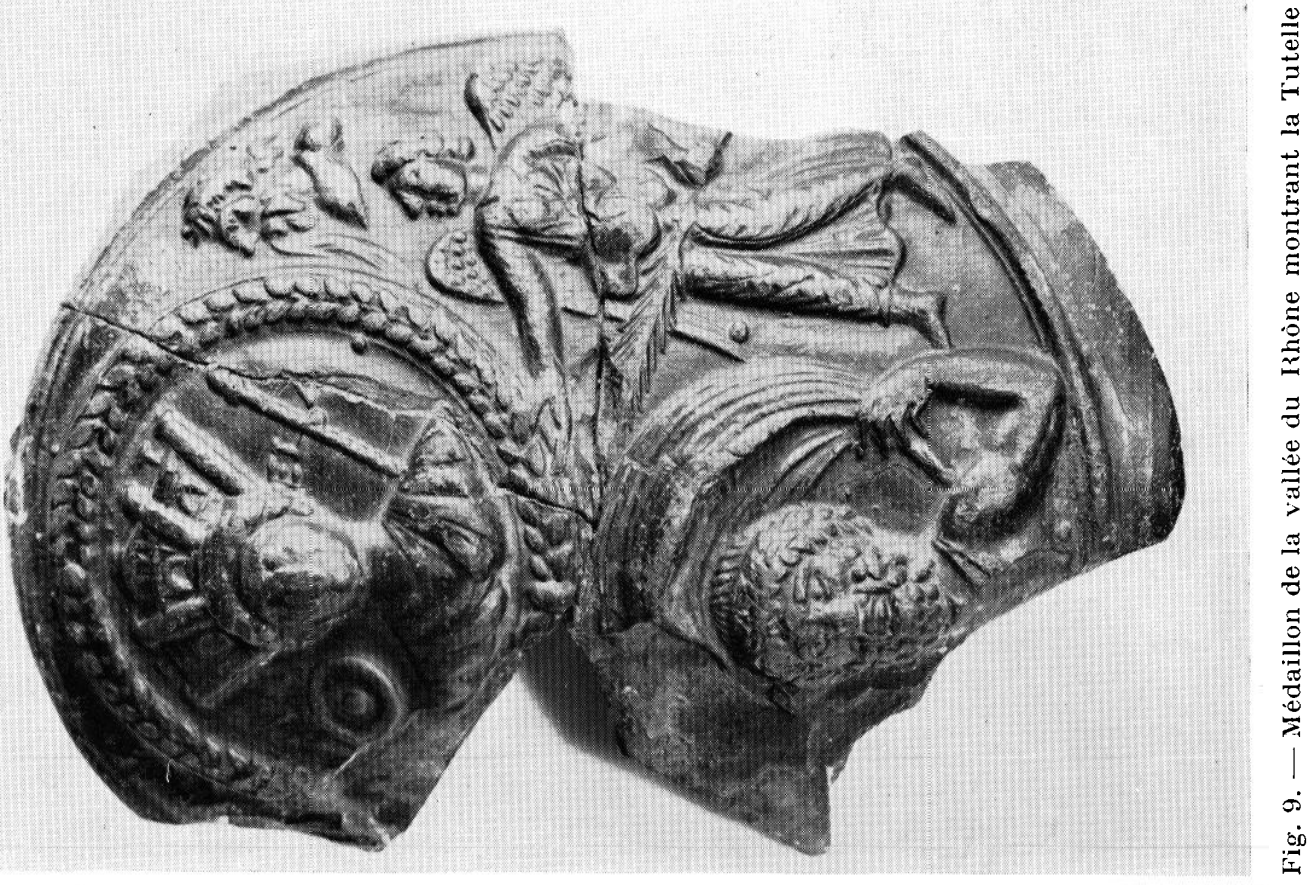


Si le relief a décoré un autel public de la colonie de Lyon, faut-il en conclure que la région de Beaujeu, d'où il provient, relevait de la colonie ? Il nous semble que la réponse est affirmative, et que Beaujeu était une bourgadefrontière sur les limites nord de la colonie.

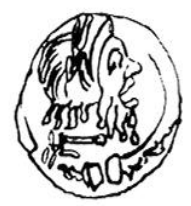

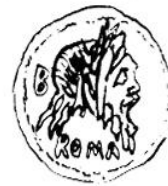

Fig. 10. - Monnaies de D. Junius Silanus, avec la représentation d'un silanus bouche ouverte. (D'après Grueber).

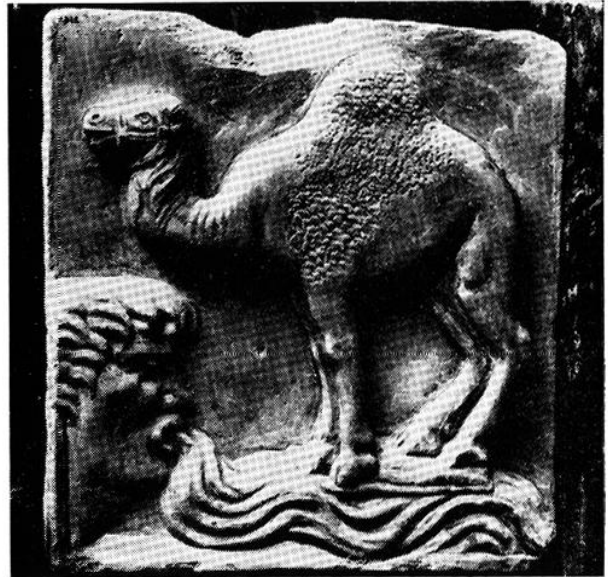

Fig. 11. - Relief de fontaine avec un masque de Fleuve. (Document de I'Institul allemand de Rome).

Ces limites sont mal connues. Aucune borne n'a été retrouvée, aucun lieudit Fines n'est signalé par les Itinéraires ou reconstitué grâce à la toponymie. L'épigraphie n'apporte pas non plus de lumières; seule de toutes les cités gauloises, Lyon appartient à la tribu Galeria; malheureusement, sur la quarantaine d'inscriptions trouvées entre Lyon et Mâcon, il n'y a pas la moindre épitaphe mentionnant la tribu du défunt.

Devant cette carence des documents, on comprend l'absence d'étude détaillée sur les frontières lyonnaises. Il semble pourtant qu'il ne faille pas désespérer; une limite nord peut être déterminée avec quelque vraisemblance, grâce à des arguments indirects, et surtout grâce à la toponymie, qui permet de retrouver l'équivalent celtique d'un lieudit Fines.

Divers indices, en effet, laissent croire que le territoire de Lyon élail limité, vers le nord, par le cours de l'Ardières, affluent de rive droite qui se jetle dans la Saône à une quarantaine de kilomètres au nord de Lyon, après avoir arrosé les bourgades de Beaujeu et Belleville (carte, fig. 12).

10 Beaujeu, sur l'Ardières, située " aux bons passages et sur la frontière des anciens pagi ", "à la frontière de l'inconstant pays lyonnais "13, esl volontiers considérée comme p. 458 .

(13) G. Dunx, La société aux onzième et douzième siècles dans Ia région mâconnaise, Paris, 1953, 


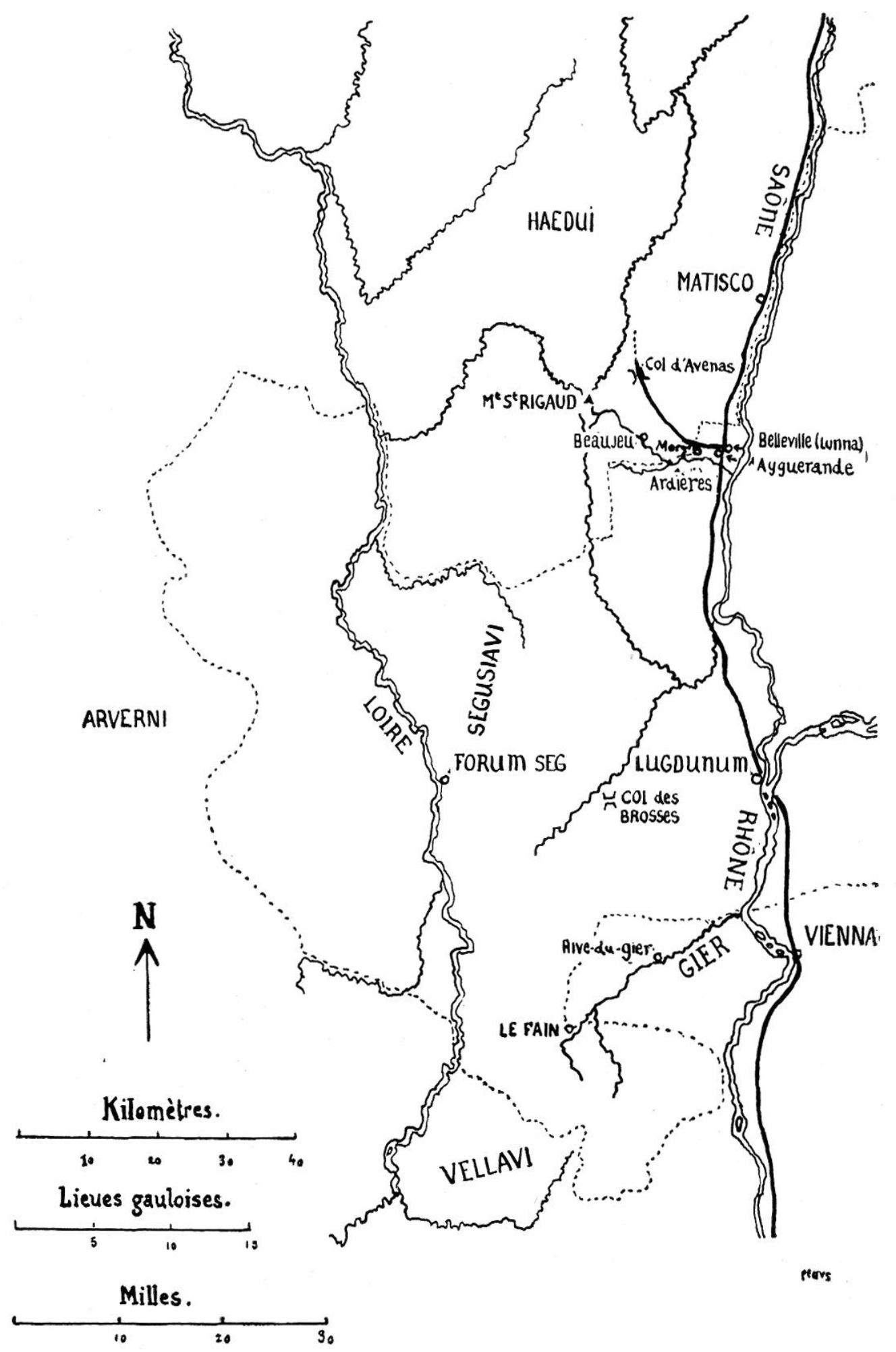

Fig. 12. - Carte des environs de Lyon et de la région de Beaujeu. Le pointillé indique les limites du diocèse de Lyon. (D'après la Carle de la Gaule au commencement du V̌e siècle, publice en 1865). 
marquant la fronlière historique de la Bourgogne et du Lyonnais. Ia bourgade est au pied du Mont saint-Rigaud (1012 mètres), où l'Ardières prend sa source, et qui constitue une barrière naturelle, dominant au nord les collines du Lyonnais et marquant le partage des eaux entre cette région et le Charolais.

$2^{\circ}$ On sait que les limites des anciens diocèses prolongent d'ordinaire celles des civilates. Celles de l'archevèché de Lyon englobent malheureusement plusieurs civilales, dont celle des Ségusiaves; sur la rive gauche de la Saòne, elles s'étendent jusque vers Nantua. On peut noter cependant que la limite de l'archevêché de Lyon et de l'évêché de Màcon faisait de Beaujeu, du còlé de Màcon, et de Belleville, du còté de Lyon, deux bourgades-fronlières ${ }^{14}$.

$3^{\circ}$ L'Itinéraire d'Antonin signale, à vingt lieues gauloises de Lyon, et à dix lieues de Màcon, l'étape de Lunna, qui correspond à peu près au bourg de Belleville, sur le confluent de l'Ardières et de la Saòne ${ }^{15}$; c'est une étape de confluent. Il semble du reste que le nom de Lunna, avant de désigner la bourgade, ait été le nom de l'Ardières elle-mème; Lunna est en effiet attesté ailleurs comme hydronyme, et représente le prototype de l'Orne-Champenoise, dite aqua de Lunna en $1098^{16}$. Il est très fréquent de voir une station porter le nom de la rivière que traversait la route ${ }^{17}$. Belleville, sur l'Ardières, est en somme une ancienne mulatio ad Lunnam, un relais près de la rivière. Etait-ce une station-frontière?

Bàtie sur l'Ardières, site de confluent et relais routier, Belleville comportait également le croisement de la route romaine qui gagnait Autun par le col d'Avenas ${ }^{18}$.

to Il y a plus. Belleville comprend un hameau du nom d'Aiguerande. On reconnaît la' ${ }^{19}$ un antique "Equoranda, toponyme de limite bien connu, dont le second élément signifie "frontière ", le tout pouvant équivaloir à "frontière d'eau " (?). On a relevé plus d'une centaine d'exemples de ce toponyme, qui permettent de reconnaitre en lui un mot qui, dans la langue gauloise mourante ${ }^{23}$, s'est fréquemment substitué au latin fines, pour désigner une station, relais, sanctuaire ou marché situé sur une voie, au passage d'une cité dans une autre ${ }^{21}$. Notre Aiguerande est sur un confluent, "à quelques kilomètres de la limite séparative des anciens diocèses de Lyon et de Màcon „22. La seule existence de ce toponyme est une invite à placer sur l'Ardières la limile nord du territoire lyonnais.

1.1) Gallia Christiana, t. IV 'éd. de 1728), carte face à la page 1. Sur la géographie historique du Lyomnais et du Vaconnais, М. Cнмгмe, Les origines du duchè de Bourgogne, $2 \mathrm{c}$ partie, Géographie hislorique, p. 1014-1070, partic. p. 1017 et 1023-1027, et cartes face aux pages 1016 et 1088 .

(15) P. W intlicumer, Le Lyon à Mâcon, REA, 41, 1939, p. 245.

(16) P. Lisber, Principes el méthodes d'hydronymie française, Paris, 1956, p. 350 et 135.

(17) A. Girmiter, dans le Manuel de Déculitetre, t. VI, vol. 2, I, les roules, p. 267.

(18) P. Wintlicumer, article cilé.

(19) P. Wirter Mier, arl. cit.; P. Lebra, Le problème d'Equoranda, Romania, 63, 1937, p. 182.

(20) Il est très croyable que ce mol, lout gaulois qu'il est, ait servi, sous l'Empire, à désigner des lieux frontières de création postérieure à la conquête romaine; cf. M. Roblin, Le lerroir de Paris aux époques gallo-romaine el franque (Paris, 1951), p. 24 et 37.

21) A. Grevifr, Manuel, Les routes, p. 177; A. DAuzat, La loponymie frangaise, p. 122 ; P. Lebir., Le problème d'Equoranda, cité ci-dessus. Mais voir maintenant, sur le sens du mot, P.-.1. Dural, RE.1, 60, 1958, p. 356 ; le fait demeure, cependant, que le toponyme 'Equoranda se rencontre surtout sur les fines: des mulaliones se dressaient-elles aux frontieres des civilales?

(22) P. LEisEr, art. cil., p. 182. 
$5^{0}$ Entre Beaujeu et Belleville, sur les collines de rive gauche qui dominent la vallée de l'Ardières, on rencontre un second toponyme de frontière : les hameaux du Haut-Morgon el du Bas-Morgon (commune de Villié-Morgon, canton de Beaujeu, Rhòne), dits in agro Morgonico en 920 . Le mot semble signifier "endroit-limite" et se trouve appliqué à des localités de frontière ${ }^{23}$.

La convergence de ces indices, et surtout l'existence d'un *Equoranda, invitent à placer la frontière nord du Lyonnais à peu près sur l'Ardières, vers Belleville et Beaujeu.

Ajoutons que, dans la même région, un autre *Equoranda est à la limite des anciens diocèses de Lyon et du Puy; un troisième, à celle des diocèses de Lyon et de Clermont ; un quatrième est à Rive-du-Gier, à 35 kilomètres au SSO de Lyon. Comme le note P. Lebel, ils doivent marquer la frontière des Ségusiaves et des Vellaves, des Ségusiaves et des Arvernes, enfin la frontière sud de la colonie de Lyon, qu'il convient ainsi de placer sur le Gier, affluent de rive droite du Rhône ; en outre, on connaît sur le Gier, à Saint-Jean-Bonnefonds, un lieudit Le Fain, c'est-à-dire Fines ${ }^{24}$.

Il est par ailleurs possible que l'Ardières, avant de séparer Lyon des Éduens, ait été la vieille frontière des Éduens et des Ségusiaves, et le Gier celle des Ségusiaves et des Vellaves ; auquel cas la région qui fut enlevée aux Ségusiaves pour constituer l'ager de la nouvelle colonie représenterait la partie orientale de l'ancien territoire de ce peuple, et aurait la forme d'une bande qui s'étendait, du nord au sud, sur toute la hauteur de ce territoire, le long de la Saône et du Rhône, de l'Ardières au Gier.

Si l'Ardières, avec Beaujeu, marquait une limite de l'ager lyonnais, l'autel public de la colonie que décorait notre relief était en somme un autel de frontière, une ara finalis ${ }^{25}$.

Nous voici en présence de plusicurs données : un autel de frontière, dédié à Cérès, à laquelle sont offerts des suovétauriles, que précède une pompa champêtre, sous la direction des personnages officiels de la colonie. Comment organiser ces données ?

Une explication parait s'imposer : la pompa et les suovétauriles constituent la cérémonic de consécration de l'autel. Il semble, en effet, que des suovétauriles marquaient la création ou la restauration d'un monument cultuel, afin de sacraliser l'espace occupé par ce monument. Les Frères Arvales célébraient un lustrum missum et offraient des suovétauriles pour la restauration d'un

(23) P. Leibl, Principes el mélhodes d'hydronymie, p. 322.

(24) P. I.racl, Le problème d'Equoranda, cité ci-dessus (no 19), p. 182-184.

(25) Ara finalis: Hrax. Grom., 199, I Lachm. 
temple ou d'un autel ${ }^{26}$; Vespasien fit de même pour celle du temple de Jupiter Capitolin : lustrala suovelaurilibus area ${ }^{22}$; la dédicace d'un trophée s'accompagnait aussi de suovétauriles ${ }^{28}$; et on a proposé récemment d'interpréter de la même manière la pompa et les suovétauriles qu'on voit sur une paroi du mithréum de Sainte-Prisca ${ }^{29}$. La colonie de Lyon, ayant élevé à Cérès une ara finalis, serait venue en pompe consacrer l'autel par des suovétauriles, sous la conduite de ses magistrats.

Explication d'autant plus séduisante qu'elle permet de comprendre la composition du relief, et qu'elle offre un parallèle illustre. On se souvient que la scène de sacrifice, qui chronologiquement vient après la pompa, a été transposée par le sculpteur au centre de la composition : l'autel, les officiants et la Cérès praesens scmblent interrompre la procession. Cette transposition est peut-être due à un simple souci de mise en vedette. Mais peut-être aussi le sculpteur a-t-il voulu faire entendre que, même si le sacrifice n'avait lieu qu'après la pompa, l'autel n'en occupait pas moins, par rapport à celle-ci, une position centrale dans l'espace : bref, que la procession lustrale tournait autour de l'autel. Les représentations de suovétauriles que l'art romain nous a laissées présentent souvent la même disposition ; le cortège lustral et la scène sacrificielle $\mathrm{y}$ sont réunis en narration continue dans le temps, comme sur le monument de Bcaujeu; et l'autel avec le sacrificateur est au centre du cercle décrit par la lustration, comme il est logique, puisque celle-ci tournait autour de l'autel pour en sacraliser l'emplacement ${ }^{30}$. Le cortège lustral se déplaçait dans le sens inverse des aiguilles d'une montre : or la pompa de Beaujeu, qui est probablement censée passer devant l'autel au moment où le sculpteur l'a saisie, est menée par les magistrats de gauche à droite : la tête du cortège, avec les deux licteurs, est à l'extrémité de droite du bas-relief (fig. 1 et 3 ).

(26) CIL, VI, 2099, 2104 B, 2107, cité par M. J. Vermaseren (v. infra, n. 29).

(27) TACITE, Hisloires, IV, 53, 4, cité par U. J. Vermaseren.

(28) G.-Ch. Picard, Les trophées romains, Paris, 1957, p. 246 et 250 , d'après un reliel' d'Isernia, étudie par II. Juhrmann, Röm. Mitt., 2, 1949, p. 45.

(29) M. J. Vermasranen, The Suovetaurilia in Roman Art, Bullelin van de vereeniging tot bevordering..., 32, 1957, p. 10. Nous interpréterions volontiers de la même manière les suovétauriles d'un autel militaire reproduit dans S. RerNacrr, Rép. Reliefs, t. 2, p. 449.

(30) Voir Inez Scotr Ryberg, Riles of Slate Religion..., ch. VIII, p. 104-119 et nombreuses figures. Citons entre autres, pour l'iconographie des suovétauriles, divers reliefs moins connus, qui ne nous intéressent pas directement ici : deux reliefs trouvés en Bulgarie, avec sacrifice des trois espèces d'animaux à Jupiter et à une Jumon assise sur un cerf comme la parèdre de Jupiter Dolichenus : G. KazArow, Archäologisches aus Bulgarien, Akad. Wiss. Wien, phil.-hist. Kl., An\%., 14-15, 1942, p. 179; ibid., 54, 19:7, p. 300 ; et un relief présentement dans le commerce des antiquilès à Rome, signalé par C. Vermliele, 1.J.t, 61, 1957, p. 115 : un homme velato capile offre des suovétauriles devant un autel ; j'en ai une photographie (ici fig. 16); comme provenance, le marchand a indiqué à M. Vermeule la Sicile, et à moi Rome. 
Nous avons donc, à Beaujeu, la lustration de consécration de l'autel à Cérès; elle tourne autour de cet autel, mais la disposition toute en longueur du relief a obligé le sculpteur d'aplatir le cercle formé par la pompa, l'autel conservant sa position centrale. Il existe un parallèle, saisissant à d'autres égards : un des reliefs de l'Ara Pacis nous fait assister à la pompa des suovétauriles qui ont marqué la constilutio de l'autel, le 4 juillet de l'an 13 avant notre ère; on y roit le cortège, ouvert par des licteurs, où se mêlent officiels et ministres en tuniques qui amènent les animaux (fig. 14). Or ce relief, comme celui de Beaujeu, constitue la décoration du couronnement de l'autel (fig. 13) ${ }^{31}$. A Beaujeu comme à l'Ara Pacis, la décoration du couronnement perpétuait donc le souvenir de l'instant origincl du monument : sa consécration par une lustration, qui avait fait le tour de l'autel, suivie de suovétauriles célébrés sur l'autel lui-même. C'est cette double scène qui est représentée sur le relief.

Alors se pose une seconde question, toute différente : pourquoi l'autel de frontière de la colonie lyonnaise était-il consacré à Cérès ?

La présence d'autels sur les limites est bien connue, qu'il s'agisse de limites de provinces, de cités ou de domaines privés ${ }^{32}$. L'agrimenseur Iygin écrit : "Des bornes, des lignes de centuriation, des rivières très souvent, et aussi des autels de pierre, limitent le territoire d'une cité et le séparent de celui de sa voisine ${ }^{33}$. Ces autels s'élevaient aux Dieux Mânes, et marquaient l'emplacement d'un tombeau ; le hasard de leur position près de la frontière les avait désignés comme des repères commodes pour les agrimenseurs ${ }^{34}$. D'autres fois, l'installation d'un autel sur les limites était intentionnelle; ils étaient alors consacrés aux Fines divinisés ${ }^{35}$, ou dédiés à l'empereur, de l'autorité de qui dépendaient les frontières. Il pouvait également arriver que l'ara finalis fût dédiée à la divinité du lieu; sur le limes de Germanie, non loin de la Saalburg,

(31) G. Moretti, Ara Pacis Auguslae, Rome, 1948, p. 182 et 280. Cest M. G. Moretti (Ara Pacis Auguslae, p. 282) qui prononce le mot de suovétauriles à propos de la frise mutilée qui court sur les sponde qui couronnent l'Autel ; il est tentant, en effet, de restituer un porc sur la partie mutilée; on ćvitera ainsi de devoir constater, avec ${ }^{\mathrm{mc}}$ Ryberg (Rites, p. 42), que "the association of a ram, steer, and heifer as a triple offering is unparalleled in Roman religion \#. Or .I. Vermaseren a montré que les suovètauriles sont un sacrifice de sacralisation; par ailleurs, un texte de Tacite (Hisl., IV, 53, 4) prouve que des suovétauriles ont accompagné la constilution du nouveau temple du Capitole (cf. E. WELIN, Die beiden Festtagen der Ara Pacis, dans Dragma Nilsson, p. 500). Si ce sont alors des suovétauriles qu'il faut restituer sur les sponde de l'Ara Pacis, n'a-t-on pas là le moyen de trancher la vieille question dedicaiioconstitutio-consecralio, et de rapporter la cérémonie figurée sur les sponde à la constitution, en l'an 13 ?

(32) A. Grenier, dans le Manuel de Déchelette, t. VI, vol. I, Généralilés, p. 172-179.

(33) Liygrs, 114, 7 Lachm.

(34) Il est très souvent question chez les Agrimenseurs des tombeaux utilisés comme limites.

(35) Espéraxdrro, Inscriptions lalines de Gaule (Narbonnaise), 누 642. 


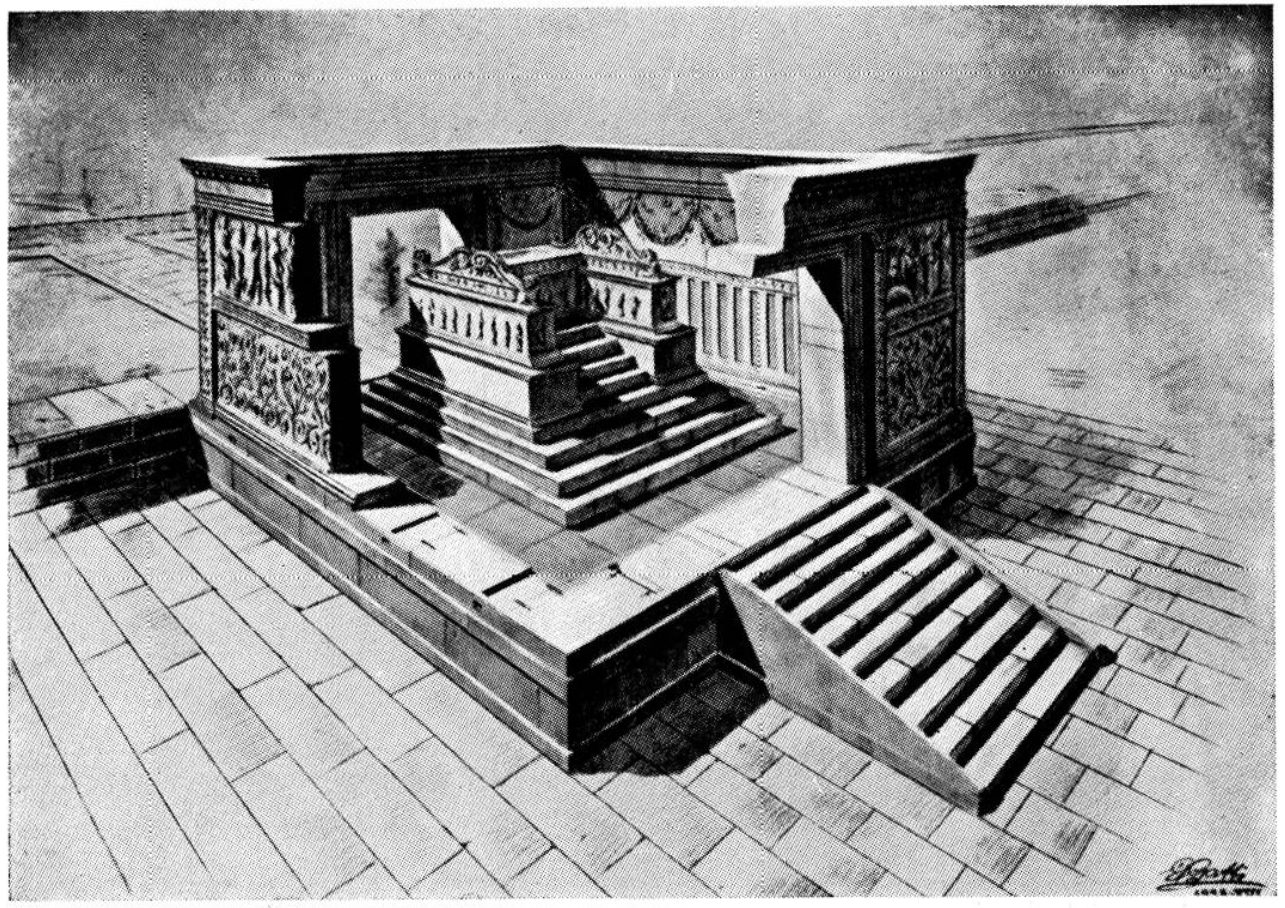

Fig. 13. - L'Ara Pacis: perspective du monument montrant l'autel et son couronnement. (D'après G. Galli).

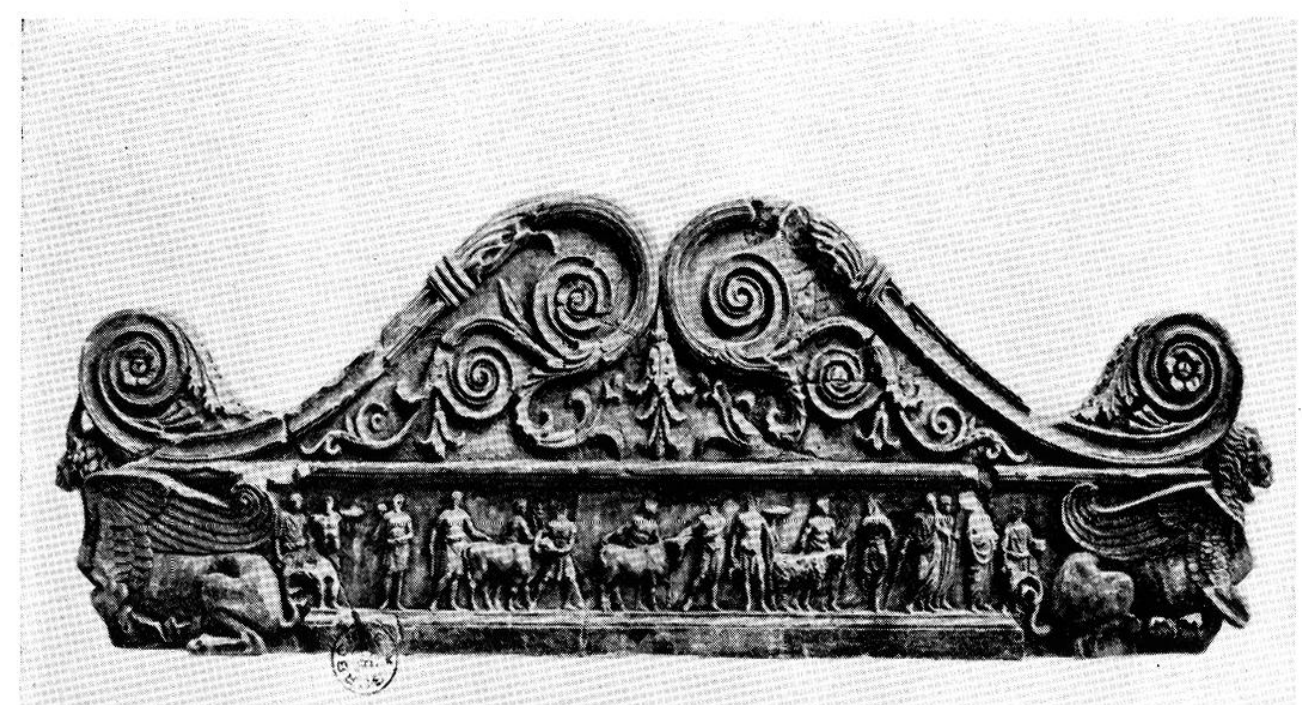

Fig. 14. - Ara Pacis: couronnement de l'autel (avec l'aimable aulorisalion de M. G. Morelli). 
aux sources du Kirdorfer Bach, une dédicace aux Nymphes marquait la limite de l'Empire romain; au-dessus de l'autel, une croix dans un cercle représente le decus des Agrimenseurs ${ }^{36}$.

Mais quel rapport entre Cérès et les limites ? Ia déesse de l'ara finalis de Beaujeu, entourée des silani qui symbolisent les fleuves du Confluent, est en relation avec l'ager lyonnais. Or il existe un complexe religieux, d'allure populaire et qui demeure pour nous fort obscur, où Cérès apparaîl en liaison avec les terroirs et leurs limites; sous l'Empire, ce complexe s'était réduit aux lustrations des pagi des cités, fêtes paysannes qui opposèrent partout, y compris en Gaule, une longue résistance au christianisme.

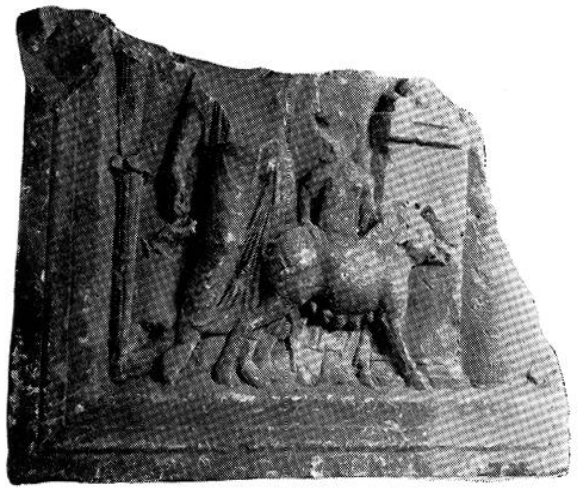

Fig. 15. - Corfinium (Pentima, Italie), Basilica Valvense. Sacrifice offert par une sacerdos Cereris. (Pholographie G. Ville, atec l'aimable autorisalion de M. 1: Cian/arani).

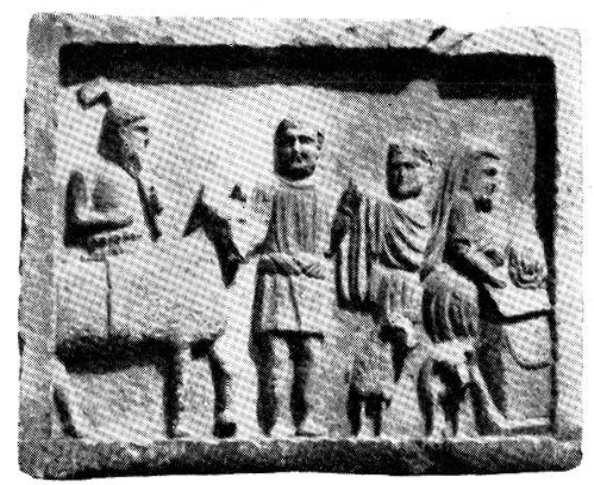

Fig. 16. -- Suovétauriles sur un relief de provenance incommuc, actuellement à Rome daus le commerce des antiquités.

La vieille religion romaine montre que Cérès, qui protégeait les récoltes d'un terroir, pouvait aisément devenir par là une protectrice des frontières, par une évolulion inverse de celle qui fil de Mars, protecteur des frontières, un dieu à compétence agraire. A Rome, parallèlement à la lustration de la ville ou Amburbium, il avait existé un vieux rite de lustration de l'ager Romanus, les Ambarralia de mai ; cetle fète rustique s'achevait par des suovétauriles a Mars. La fète de mai des Frères Arvales prit la succession de cette antique cérémonie ; elle avait lieu à cinq milles de Rome, sur un point de la frontière de l'ager Romanus antiquus, et, désormais, les suovétauriles qui clòturaient la solennité étaient ofterts à Cérès ${ }^{37}$.

Déesse des frontières, Cérès se voyail nécessairement honorée par une lustration et des suovétauriles, puisque ces rites avaient pour valeur de sacraliser un espace après en avoir parcouru les limites. Les cités d'Italie centrale en fournissenl un exemple; le culte de Cérès y était célébré par des prêtresses municipales, sacerdotes publicae Cereris;

(36) A. Grevirr, ouvrage cité, p. 175-177, fig.

(37) H. I.: Boxvirc, Le culle de Cérès à Rome, Paris, 1958, p. 141-148. 
ce culte pourait consister en l'immolation d'une truie (on offrail des truies à Déméter), mais aussi en suovétauriles : un relief perdu de Carsioli en fait foi ; un autre, conservé à Corfinium, également (fig. 15) ${ }^{38}$.

Prévenons une objection possible : a Carsioli est attesté un culte municipal de Cérès, avec des suovétauriles qui ont élé nécessairement précédés d'une lustralio agri; le relief de Beaujeu ne s'expliquerait-il pas semblablement par un culte municipal de Cérès? Mais un pareil culte, qui semble du reste ètre tombé assez tòt en désuétude, est propre a l'Italie centrale et s'explique par son passé religieux ; il serait non moins invraisemblable d'en supposer l'équivalent en Gaule que de postuler qu'il existait à Lyon un équivalent municipal de la fête de mai des Arvales.

Il est en revanche une fête de Cérès qui était très populaire sous l'Empire, en Gaule comme ailleurs : la lustration des pagi rustiques au début de l'été; le cadre où se déroulait celte fète n'était pas la cité, mais le pagus, et les magistrats municipaux ne devaient guère s'intéresser à cette fêt..e de rustres ; aussi bien nous cst-elle surtout connue à basse époque, pour la résistance qu'clle opposa au christianisme.

Les Agrimenseurs et quelques inscriptions attestent qu'en Italie les pagi étaient lustrés par les soins de leurs ofliciels, les magistri pagorum. Traitant des controverses qui pouvaient s'élever entre cités au sujet de la délimination de leurs territoires respectifs, Siculus Flaccus ajoute ${ }^{39}:$ " Mais les pagi eux-mêmes ont souvent des limites nettement reconnaissables. En ce qui concerne ces pagi, je ne pense pas que la question puisse se poser de savoir à quel territoire municipal ils appartiennent, mais seulement jusqu'où s'étend ce territoire. Eh bien, c'est ce que permet déjà de reconnaître la lustration du pagus à laquelle les magistri pagorum ont eu coutume de procéder (vel ex hoc, magistri pagorum quod pagos lustrare soliti sunt); il faut considérer alors que le territoire s'étend jusqu'où ils menaient leur lustration (quatenus lustrarent) ". Ne seraitce pas des suovétauriles célćbrés par un magister pagi, qui sont figurés sur un relief présentement dans le commerce des antiquités à Rome (fig. 16)?

Selon toute vraisemblance, celte lustratio pagi se confond avec la cérémonie de lustration des moissons mûrissantes que les menologia rustica placent en mai : SEGETES LVSTRANTVR ; on y sacrifiait des hostiae lustrales, et les pagani pouvaient faire suivre la fête de plusieurs jours de bombance ${ }^{\mathbf{4 0}}$. Virgile évoque cette réjouissance, ou d'autres toutes semblables ${ }^{41}$ :

(38) Les sacerdotes publicae Cereris sont altestees par des inscriptions à Anzio, Formies, Capoue, Pouzzoles, Pompéi, Cassino, Sorrente, Carsioli, Corfinium, Pinna, Isernia, Sulmona, etc. Le relief de Carsioli ave des suovetauriles est au CIL, IX, 4052; je remercie 1 . Cianfarani, surintendant des Antiquités pour les Abruzzes et le Molise, qui a bien voulu rechercher, en vain, le document; je l'ai persomnellement recherché non moins vainement. - Par ailleurs, un relief conservé à la Basilica Valvense de Corfinium (signale, mais non reproduil, dans Notiz. Scav., 1899, 399) représente le sacrifice à Cérès d'une truie par une sacerdos publica; je remercie I. Cianfarani, qui m'a autorisé à photographier et reproduire le document, et mon ami Georges Ville, qui en a exécuté pour moi un remarquable cliché (ici fig. 15).

(39) Sictides Flaccis, 164, 25 Jachm.

(40) CIL, I (2), p. 280-281; IX, 5565; IX, 1618.

(11) Sur ce texte difficile, P. Grisal, La cinquième églogue et le culte de César, Mélanges Ch. P'icurd, t. I, p. 412 ; H. I.: Boxisec, Ie culle de Cérès à Rome, p. 134. 
In primis venerare deos, atque annua magnae sacra refer Cereri, laetis operatus in herbis (...). Cuncta tibi Cererem pubes agrestis adoret, cui tu lacte favos et miti dilue Baccho; terque novas circum felix eal hostia fruges omnis quam chorus et socii comitentur ovantes, et Cererem clamore vocent in lecta (....).

Cette lustration des champs, en effet, se faisait en l'honneur de Cérès.

Ces fètes populaires sont encore attestées à basse époque. En 397, aux environs de Trente, trois évangélisateurs, Sisinnius, Alexandre et Martyrius, furent massacrés par une foule de paysans furieux. Venus pour instruire dans la foi les campagnards du Trentin, ils avaient bâti une église à une quinzaine de kilomètres au NO de la ville, au Val di Non. C'est là qu'ils se heurtèrent à la procession rustique du lustrum, que Saint-Vigile-de-Trente, qui écrit au lendemain de l'évènement, décrit en termes significatifs : "... cum (rustici) lustrale malum circa fines agrorum cuperent ducere scena ferali, et sata nascentia tam protererent quam foedarent, luctuosis ornatibus coronati, ululato carmine diaboli, diversarum pecorum pompis ${ }^{42}$.

En Gaule même, comment ne pas songer au martyre de Saint-Symphoriend'Autun ? La Vila et Grégoire de Tours nous disent qu'à l'époque où vécut ce martyr - on ne sait si elle se place au second ou au troisième siècle —, les gens d'Autun promenaient solennellement une statue de Cybèlc (Berecintia) à travcrs leurs campagnes ${ }^{43}$; de Cybèle à Cérès, il n'y a pas loinn ${ }^{44}$ d'Autun à Lyon, non plus : ces civitates sont voisines.

Il n'est pas question de tout brouiller, et d'attribuer à la colonie de Lyon et à ses magistrats une fête rustique propre aux pagani, alors que rien ne pcrmet de croire que ces réjouissances campagnardes en l'honneur de Cérès aient jamais fail partie des cultes officiels des cités. La lustration autour de l'autel et les suovétauriles qui sont figurés sur le relief de Beaujeu représentent la consécration de l'ara finalis, rien de plus ; la présence des magistrats municipaux et le parallélisme de l'Ara Pacis suffisent à nous en avertir. Mais on comprend pourquoi

(42) Saint Vigile dans Migne, P. L., XIII, 553 (cf. Saint-Maxime-de-Turin, Migne, P. L., LVII, 696) ; textes réunis dans Acta Sanct., mai, t. VII, p. 38 ; Dict. d'hist. et de géogr. eccl., s. v. Alexander $n^{\circ} 24$. La fête de ces martyrs est le 29 mai dans le martyrologe hiéronymien.

(43) Rusarr, Acta sincera (éd. de 1859), p. 125, cité par J. Zwicker, Fontes historiae religionis Cellicae, p. 163; Grígorre de Tovrs, De gloria confessorum, 76, dans Zwicker, p. 180. Fête le 22 aoùt dans le martyrologe hiéronymien.

(44) Il ne faut sans doute pas attacher un sens trop précis à cette mention de la Bérécyntienne par Grégoire de Tours; il a voulu simplement parler d'une déesse, protectrice des terroirs. - Citons encore Sulpice Sévère, Vila S. Marl., 12 : "Haec Gallorum rusticis consuetudo, simulacra dacmonum candido tecta velamine misera per agrros suos circumferre dementia ”. 
cet autel élcvé en pleine campagne, près de la frontière, avait été dédié à Cérès : c'est en l'honneur de Cćrès, protectrice de leur Lerroir, que les pagani du voisinage menaient la lustration de leurs champs et la poussaient jusqu'à la frontière (qualenus lustrarent, dit Siculus Flaccus); sans doute l'autel fut-il élevé en un point de la frontière où aboulissait d'ordinaire la lustration ; on peut croire qu'après sa construction les choses continuèrent de la même manière, et que ce fut désormais devant l'autel que les paysans offrirent les suovétauriles qui clôturaient sans doute la lustration de leur pagus.

Le monument de Beaujeu est le débris d'une somptucuse ara finalis que la colonie de Lyon avait élevé pour marquer ses frontières; le relief représente la consécration de cet autel. Dressé en pleine campagne, sur les fines, l'autel fut dédić à Cérès, protectrice des terroirs et de leurs limites, et était probablement en relation avec la lustration que les payani des alentours menaient chaque année, en l'honneur de Cérès, jusqu'aux extrémités de leur finage.

Paul Verie. 